\title{
O topos do jogral no acervo mariano medieval
}

Viviane Cunha

Universidade Federal de Minas Gerais

\begin{abstract}
religiosidade e a expressão do maravilhoso são dois lugares comuns da poética medieval em língua vulgar. A partir desses dois pressupostos, o principal objetivo deste trabalho é apontar para uma das formas de expressão da fé na Idade Média - as narrativas de milagres - a fim de mostrar conjuntamente a presença do maravilhoso na canção francesa Du cyerge qui descendi sus la vièle au vieleeur devant l'ymage Nostre Dame, de Gautier de Coinci, e na Cantiga de Santa Maria número 8: Esta é como Santa Maria fez en Rocamador decender ha candea na viola do jograr que cantava ant' ela; partindo de um relato de milagre em latim.

A figura de Maria começou a despertar o interesse dos eruditos desde a antiguidade, uma vez que os evangelistas foram pouco prolixos em relação a esse tema. Num breve percurso histórico sobre os principais eruditos/teólogos que se dedicaram aos estudos marianos, há que citar-se o precursor São Justino (165), que se referiu a Ela como a "Virgem" e formulou o binômio Eva-Maria. Santo Irineu, bispo de Lyon entre 173/ 178, esboçou uma teoria sobre Maria (in Adversus Aereses), na qual denominou-a "Mãe da Igreja", e considerou-a como uma "Nova Eva" que veio para redimir a humanidade dos pecados cometidos pela primeira mulher. Orígenes (185-254), teólogo da escola de Alexandria, utilizou a expressão Theotokos (gr.) ou Dei Genitrix (lat.) 'Mãe de Deus', para se referir a Maria, termo que
\end{abstract}


foi incorporado à liturgia oriental, desde a primeira metade do século III.

Os Pais da Igreja foram os primeiros cantores de Maria, particularmente, Santo Ambrósio de Milão, São Jerônimo e Santo Agostinho que enriqueceram os estudos marianos do ponto de vista teórico; e nos séculos VII e VIII São João Damasceno, ajudou a propagar a veneração mariana no Oriente. Posteriormente, a veneração popular e a reflexão dos intelectuais engrandeceram a imagem de Maria, e a associaram aos grandes milagres. Bernardo de Claraval foi um desses eruditos, que no século XII aderiram ao culto de Maria; e foi possivelmente o autor da Salve Rainha.

O culto mariano teve a sua origem no Oriente. O Concílio de Éfeso, em 431, proclamou Maria como "Mãe de Deus", em reação contra Nestorius, patriarca de Constantinopla, que via nela apenas uma pessoa humana, a mãe de Jesus. Esse culto passou ao Ocidente no século V, e a partir do século XI, conheceu o seu apogeu no tempo das catedrais, tendo sido a maioria delas consagradas a Nossa Senhora, principalmente, na França: Notre Dame la Grande (em Poitiers), Notre Dame de Paris, Notre Dame de Chartres, Notre Dame des Ardents (em Arras), Notre Dame de Amiens, Notre Dame de Laon, Notre Dame de Puy, Notre Dame de Rouen, para citar apenas as principais.

A devoção a Maria apareceu primeiramente na liturgia. No que se refere aos milagres a Ela atribuídos, ou com a sua intervenção, desde o século VI Gregório de Tours mostrou no seu Liber Miraculorum - do qual constam seis narrativas orientais - o fervor dos fiéis por tudo que se referia à Virgem. Entretanto, foi a partir do século XI, que começaram a surgir as coleções marianas com maioria de milagres de origem ocidental, e já no século XII, apareceram as grandes compilações, nas quais foram reunidos milagres de interesse geral, quaisquer que fossem suas origens. As primeiras compilações de milagres 
marianos foram redigidas na Inglaterra, tendo particular importância a recolha de Guilherme de Malmesbury: De miraculis beatae Virginis Mariae. Desde então, espalharam-se rapidamente por toda a Europa.

$\mathrm{O}$ culto mariano na Europa atingiu o seu apogeu no século XII, e continuou florescente no século XIII. Esses dois séculos que coincidiram com o trovadorismo, enquanto fenômeno pan-românico, colocou Maria no cerne da questão da fin'amors; comparava-se a imagem do cristão prostrado aos pés de Nossa Senhora com a imagem do trovador quando suplicava à dama o seu amor. Essa aproximação se tornaria um topos bastante explorado pelos trovadores. Afonso X, rei de Leão e Castela, apresenta-se como trovador da Virgem, no Prólogo das Cantigas de Santa Maria, à maneira do trovador que suplica à sua amada nas cantigas profanas. $\mathrm{O}$ tema mariano não passou indiferente aos trovadores do Midi francês, porém, não teve o mesmo alcance que no Norte da França e na Península Ibérica. Entre os trovadores provençais que trataram da mesma temática há que citar-se Peire Cardenal - com a canção de louvor Vera Vergena, considerada uma das mais belas sobre a Virgem Maria -, Guiraut de Riquier e alguns outros.

As narrativas de milagres marianos constituem um dos gêneros mais difundidos da literatura medieval; desde o começo do século XI, os textos em latim relatavam os milagres atribuídos à Virgem. Uma dessas primeiras coletâneas foi o Livro de milagres de Rocamador, do século XII, o qual apresenta 126 narrativas em prosa latina. Esse gênero se desenvolveu principalmente no século XIII, como comprovam os Miracles de Nostre-Dame, de Gautier de Coincy; Speculum historiale, de Vincent de Beauvais (ca.1244); Miracle de Théophile, de Rutebeuf (ca. 1260), Milagros de Nuestra Señora, de Gonzalo de Berceo, e finalmente a mais importante recolha - pelo número de poemas - as Cantigas de Santa Maria, de Afonso X, que nos chegaram com a música. 
Entretanto, a primeira recolha de milagres em língua vulgar é originária da Inglaterra. Trata-se do Gracial de Adgar (como é conhecido), em língua anglo-normanda, uma coletânea de 49 milagres da Virgem, em octossílabos, da qual o suposto autor apresenta duas versões: uma de 1165-1170, e outra de 1175-1195. De Adgar, apenas se sabe que foi um clérigo de fins do século XII, possivelmente um vigário da Igreja de Santa Maria Madalena, em Londres. A fonte do Gracial foi um volume conservado na catedral deSaint Paul, escrito por mestre Alberic (ca.1160), um compilador da recolha de milagres de Guilherme de Malmesbury. Muitos dos milagres do Gracial se passam na Inglaterra, outros na França, em Chartres. O Gracial é a mais antiga tradução dos milagres da Virgem em língua românica, precedendo mesmo os Miracles de Nostre Dame, de Gautier de Coinci.

Efetivamente, Gautier de Coinci foi o nome mais expressivo em língua d'oil, no que concerne aos cantares marianos. Os seus Miracles de Nostre Dame formam uma obra importante, a qual reúne inúmeros milagres associados à Virgem. O poeta assegura que encontrou tais narrativas de milagres, num manuscrito latino. Trata-se, efetivamente, do livro de milagres de Rocamador, acima citado, no qual encontram-se muitos dos milagres que foram traduzidos do latim e recriados em versos. A riqueza de detalhes de tais textos proporciona uma idéia do imaginário medieval, além de eles fornecerem inúmeros topoi bíblicos, refundidos e remanejados pelo lirismo do medievo.

$\mathrm{Na}$ Espanha, os Milagros de Nuestra Señora, de Gonzalo de Berceo-escritos na variante riojana do espanhol, por volta de 1260, já no final de sua vida - reúnem 25 histórias mostrando a intervenção miraculosa da Virgem em favor de seus devotos. São poemas piedosos, escritos em cuaderna via, em versos alexandrinos, e na maioria, a Virgem Maria atua como intercessora entre Deus e os homens. Na corte de Afonso X, há que se mencionar o Liber Mariae, de Juan Gil de Zamora (em prosa latina) que exalta, na mesma época, o tema mariano. $\mathrm{O}$ culto a 
Maria irá inspirar principalmente as admiráveis Cantigas de Santa Maria, redigidas durante o reinado do rei Afonso X, o Sábio (que se estendeu de 1221 até 1284), escritas em galego-português, sob o modelo do zéjel (forma da poesia árabe-andaluza).

O topos do jogral de Nossa Senhora - que canta o seu louvor a Ela - é muito produtivo nos textos piedosos medievais. Pelo menos, três narrativas, bastante difundidas no universo românico dos séculos XII e XIII, apresentam-no como personagem possuidor de uma fé profunda, também ocupando aí uma parte importante o maravilhoso. O ponto de partida é uma narrativa que se encontra no livro de milagres de Rocamador, o milagre XXXIV: De cereo modulo qui auper vidulam descendit 'Da vela que desceu sobre uma viela', que narra a história do jogral Petrus Iverni (originário de Sigelar, cidade situada na região do Reno, na Alemanha), que vai a Rocamador prestar sua homenagem à Virgem.

O Livro de Milagres de Rocamador (Le Livre de Miracles de Rocamadour) é certamente uma das coletâneas mais célebres do século XII. Desde a sua redação foi copiado, lido e divulgado em toda a Europa (ALBE e ROCACHER, 1975, p. 24). Os personagens e os acontecimentos históricos, algumas vezes nele registrados, permitem datar os milagres a partir de 1148 . Dessa forma, tais milagres possuem um duplo caráter: factual e ficcional. A mistura do factum e do fictum é um traço da literatura medieval, na qual a presença do maravilhoso é uma constante. Isso se percebe não apenas na literatura, mas também, nas artes visuais. Segundo a concepção mais tradicional, o milagre é considerado como um fato que ultrapassa as leis da natureza, devido ao seu caráter inesperado, súbito ou excepcional, é um signo do sagrado. Essa doutrina, consagrada em São Tomás de Aquino (Summa Theologica, 2-2, q.178,1-3), está associada à popularidade do culto mariano.

A narrativa que é objeto deste estudo apresenta a seguinte sinopse: todos os dias em que ia ao santuário de Rocamador o 
jogral Pedro Ivern, depois que fazia a sua prece, rogava à Virgem que lhe enviasse uma daquelas velas que iluminavam a igreja fazendo-a pousar no seu instrumento. Certo dia, o milagre se realizou; uma vela desceu do lustre e pousou na viela do jogral. O monge Gérard, encarregado de guardar a igreja, ficou intrigado ao ver o que acontecera, pensando tratarse de magia; ele acusou o jogral de feiticeiro, e levou a vela de volta para o altar. Entretanto, a vela desceu mais duas vezes sobre a viela do jogral; na terceira vez, a multidão, assim como o monge Gérard, finalmente compreenderam o milagre, e para festejá-lo começaram a tocar os sinos. Todos os anos o jogral, enquanto viveu, retornou a Rocamador, levando um círio, para homenagear a Virgem. Apresento abaixo a tradução do início do texto latino, cujo original encontra-se no apêndice:

Pedro Iverni, de Sigelar, ganhava docemente a vida tocando sua viela. Ele tinha o hábito, quando chegava a uma igreja, depois de fazer a sua prece, de tocar as cordas de seu instrumento, para celebrar os louvores de Deus. Indo um dia à basílica de Nossa Senhora de Rocamador tocou infatigavelmente a sua viela, durante muito tempo, e depois, juntando aos sons do instrumento os acordes de sua voz, dirigiu os olhos para a estátua: "Oh minha Soberana, disse ele, se meu canto e minha música vos agradam e a vosso Filho, meu Senhor e Mestre, envia-me uma dessas velas, aqui suspensas, das quais não saberei precisar nem o valor, nem o número delas". Unindo o jogral sua prece ao canto, uma vela logo desceu do lustre instalando-se no seu instrumento, diante de todos os assistentes (...).

Numa narrativa em versos, Gautier de Coinci utilizou o mesmo topos do texto latino acima referido, com o engenho e a arte que lhe são peculiares. Devido à extensão da cantiga não farei aqui uma análise detalhada, pois o objetivo deste estudo, num primeiro momento, é mostrar os topoi comuns entre a canção francesa e a Cantiga de Santa Maria, e para isto apresento 
- em primeiro plano - a minha tradução a partir do texto em francês antigo (tradução que não pretende ser poética) na intenção de apresentar ao público lusófono esta pequena jóia do repertório mariano medieval; o texto original de Gautier de Coinci será apresentado em apêndice. Alguns recortes, sem prejuízos semânticos, foram feitos, por causa da extensão do poema - mais de 600 versos - o que ultrapassaria o objetivo de um simples artigo.

Da vela que desceu sobre a viela do jogral diante da imagem de Nossa Senhora

Minha viela / quer tocar uma bela ária, / sobre a Bela, / por todos estimada, / e em quem Deus, em outra época, / tornou-se humano, / e sobre a qual cantam os anjos e os arcanjos / em alta voz, no Paraíso.

A doce Mãe do Criador / na igreja de Rocamador / fez tantos milagres, e tantas coisas nobres, / que, [sobre isso foi escrito um grande livro ] / muitas vezes eu o li. / Nele encontrei um grande milagre / que aconteceu com um jogral, um homem leigo, / do qual gostaria de vos falar, se eu puder, / para que todas as almas conheçam / a cortesia de Nossa Senhora.

Na região havia um jogral / que cantava com prazer o lai / da Mãe do Salvador, / quando ia à igreja. / Era um menestrel de renome, / chamado Pierre de Siglar. / Parece-me que ele foi a Rocamador, / onde muitas pessoas sempre se reuniam / em peregrinação. / [...] O jogral tirou sua viela, / colocou o arco sobre as cordas, / e fez vibrar seu instrumento. / Logo todos se amontoaram em volta dele, / clérigos e leigos.

Quem quiser ter uma alma fiel e leal / deve chamar Nossa Senhora, noite e dia; / e por ela rejeitar o amor insensato. / Quem não a ama com um coração terno / pode-se dizer: é um miserável. 
[Pierre percebeu que todos o escutavam / E todos os ouvidos para ele se voltavam,] / quando saudou docemente / e louvou por muito tempo / a mãe de Deus, com todo seu coração. / Inclinou-se diante de sua imagem / e proclamou em forte voz: / "Oh mãe do Rei que tudo criou, / dama de cortesia, / se o que eu canto te agrada, / peço-te uma recompensa / que com uma destas velas me presenteies / Dama sem igual e sem par, / envia-me uma destas velas pascais / para iluminar o meu jantar".

Nossa Senhora Santa Maria, / que é fonte de cortesia / e verdadeira fonte de doçura, / ouviu bem a sua voz; / pois, imediatamente, sem mais esperar, / Ela fez descer sobre a viela / para que todos vissem / uma bonita vela e muito grande.

Aquele ou aquela / que serve devotamente / à Virgem / em quem Deus encarnou, / para nossa redenção, / tem um leito pronto no céu, / bem como um quarto e uma morada.

Um monge chamado Gérard, / que guardava a igreja / era odioso e malvado, / e observava todas essas coisas, / com muita amargura. / Ele considerava esse milagre uma loucura. / Chamava Pierre de feiticeiro, / de ladrão e de enganador. / Tomou a vela de suas mãos, / levou-a ao altar e colocou-a no seu lugar.

O sábio menestrel, / percebeu que o monge era teimoso e imbecil, / ele pegou novamente a sua viela / e levantou seu olhar em direção [à imagem da Virgem.] / Cantou e tocou tão bem / que não houve Sequentia, nem Kyrie / que você [ouvinte] / não teria deixado de apreciar muito. / E a vela, bela e inteira, / sobre a viela desceu novamente/ 500 fiéis foram testemunhas desse milagre. [...] Todos se maravilharam e se persignaram / e apontaram para a vela / que já descera duas vezes. / Pierre, [que ainda se encontrava perplexo] / não tinha mais os dedos sobre a viela, / mas ele cantava e tocava tão bem / diante da imagem de Nossa Senhora, / que fez chorar de piedade mais de uma alma. / Pouco 
importou o som que saiu de sua viela / seu coração cantou e tocou tão bem, / que seu nome se elevou a Deus, / pois, imediatamente, [como li no livro,] / até o menestrel - que Deus o salve - / Ela fez descer a vela, uma terceira vez. / Três vezes, a Dama - que o compreendia melhor que o monge - concedeu-lhe esse milagre; / Ela era bem mais gentil do que o monge / que ficou atordoado com o barulho / ao ver as pessoas gritando: "toquem, toquem os sinos! / Um milagre tão belo como esse nunca aconteceu / e acreditamos que nunca mais acontecerá"!

Virgem Pura / por quem Deus purificou o mundo / purifica-me, para que eu possa subir ao Paraíso; / Teus amigos subiram realmente a montanha, / Teus amigos subiram / diretamente ao céu, [e estão] diante de Deus.

Viu-se o menestrel / oferecer a vela sobre o altar [...] / Ele era principalmente cortês, valoroso e sábio, / mesmo quando ainda vivia, / cada ano, como eu li no livro, / ele trazia uma bela vela pascal a Rocamador, / a qual pesava uma libra. / Ele se regozijava de servir a Deus / e quando Deus quis que chegasse o seu fim / entrou na glória do céu. / E diante de Deus sua alma chegou, / pelas preces de Nossa Senhora / para quem ele cantava de boa vontade, / e a quem levava sempre uma vela [...] / A voz clara, agradável e bela, / o som da harpa e da viela, / do saltério, do órgão e da rabeca, / não agradam tanto a Deus, / se não houver devoção no coração./ Deus escuta a intenção, / não a voz, nem o instrumento. [Para] louvar a Deus docemente [...] / cantemos nossos melhores kyries, / nossas sequentias e hinos belos.

Nossa viela soará alta e clara / e nossos cantos serão bons e belos.

Porta do Céu, / Ponte e caminho do Paraíso, / Fonte de mel, / Vaso e Fonte de Doçura, / proteja-nos do inferno, / que é tão profundo; / quem não o teme é insano, / pois lá não há rio, nem fonte./ Doce Dama,/ com esta prece verdadeiramente 
sincera/ ponho meu corpo e minha alma/ sob a tua proteção./ Reze, sem demora, ao teu doce filho, / para que Ele faça-nos todos / viver na eternidade. / Amém.

Os Miracles de Nostre Dame, de Gautier de Coinci, constituem um conjunto de aproximadamente 30.000 a 40.000 versos. As suas canções de louvor à Virgem podem ser datadas de 1214 a 1233, época de sua atividade literária. A popularidade e a importância dos poemas do poeta francês sobre Maria estão ligadas ao fato de terem sobrevivido em mais de 80 fontes (22 deles com a música) e de terem inspirado numerosas imitações - lembrando que a imitação é uma prática corrente na Idade Média, e não tem o mesmo sentido atual.

As narrativas miraculosas caracterizam-se pelo "realismo", pela simplicidade, e uma de suas particularidades - nos séculos XII e XIII, no espaço românico - é colocar a Virgem em primeiro lugar, como intermediária entre Seu Filho, ou como consoladora daqueles que sofrem ou que a invocam simplesmente por devoção. A Virgem, intermediária entre o homem e a sociedade, o é também entre o homem e si mesmo, o que está bem representado na canção do jogral e sua viela.

Para o homem da Idade Média, o milagre é antes de tudo o que engendra o encantamento; tendo esse vocábulo se originado do latim mirum; logo, o que provoca admiração remete ao milagre no sentido amplo do termo.

A tomada de consciência do sagrado, nos espetáculos da natureza e na vida humana, provoca a emoção do homem medieval. Ele sente, sem cessar, necessidade de se extasiar, de se distrair, de chorar, de vibrar. Antes de tudo, a sua atitude de adoração é feita de um profundo sentimento diante das maravilhas de Deus. ${ }^{1}$

${ }^{1}$ ALBE; ROCACHER, 1975, p. 24. 
A narrativa do milagre do jogral de Nossa Senhora foi seguidamente reproduzida, e, conforme disse anteriormente, também na Cantiga de Santa Maria ${ }^{\circ} 8$, o que permite observar o seu percurso na Península Ibérica, em que ele é nomeado Pedro de Sigrar:

Cantiga de Santa Maria - 8

Esta é como Santa Maria fez en Rocamador decender ha candea na viola do jograr que cantava ant' ela.

A Virgen Santa Maria todos a loar devemos, cantand' e con alegria, quantos seu ben atendemos.

E por aquest' un miragre | vos direi, de que sabor averedes poy-l' oirdes, | que fez en Rocamador a Virgen Santa Maria, | Madre de Nostro Sennor; ora oyd' o miragre, | e nos contar-vo-lo-emos.

A Virgen Santa Maria...

Un jograr, de que seu nome | era Pedro de Sigrar, que mui ben cantar sabia | e mui mellor violar, e en toda-las eigrejas | da Virgen que non á par un seu lais senpre dizia, | per quant' en nos aprendemos.

A Virgen Santa Maria...

O lais que ele cantava | era da Madre de Deus, estand' ant' a sa omagen, | chorando dos ollos seus; e pois diss': «Ai, Groriosa, | se vos prazen estes meus cantares, ha candea | nos dade a que cemos.»

A Virgen Santa Maria...

De com' o jograr cantava | Santa Maria prazer ouv', e fez-lle na viola | ha candea decer; may-lo monge tesoureiro | foi-lla da mão toller, dizend': «Encantador sodes, | e non vo-la leixaremos. 
A Virgen Santa Maria...

Mas o jograr, que na Virgen | tia seu coraçon, non quis leixar seus cantares, | e a candea enton ar pousou-lle na viola; | mas o frade mui felon tolleu-lla outra vegada | mais toste ca vos dizemos.

A Virgen Santa Maria...

Pois a candea fillada $\mid$ ouv' $^{\prime}$ aquel monge des i ao jograr da viola, | foy-a põer ben ali $\mathrm{u} \mathrm{x}^{\prime}$ ant' estav', e atou-a | mui de rrig' e diss' assi:

«Don jograr, se a levardes, | por sabedor vos terremos.»

A Virgen Santa Maria...

O jograr por tod' aquesto | non deu ren, mas violou como $x^{\prime}$ ante violava, | e a candea pousou outra vez ena vyola; | mas o monge lla cuidou fillar, mas disse-1l' a gente: | «Esto vos non sofreremos.»

A Virgen Santa Maria...

Poi-lo monge perfiado | aqueste miragre vyu, entendeu que muit' errara, | e logo ss' arrepentiu; e ant' o jograr en terra | se deitou e lle pedyu perdon por Santa Maria, | en que vos e nos creemos.

A Virgen Santa Maria...

Poy-la Virgen groriosa | fez este miragr' atal, que deu ao jograr dõa | e converteu o negral monge, dali adeante | cad' an' un grand' estadal lle trouxe a ssa eigreja | o jograr que dit' avemos.

A Virgen Santa Maria... ${ }^{2}$

${ }^{2}$ METTMANN, 1981, p. 77-79, v. I. 
Tanto a canção em língua d'oill, quanto a cantiga galegoportuguesa - ambas narrativas poéticas - apresentam louvores à Virgem, no refrão. O texto do poeta francês apresenta refrães múltiplos, que evocam as litanias de Maria: Virge monde, Porte dou ciel. A cantiga de Santa Maria apresenta um refrão único: $A$ Virgen Santa Maria / todos a loar devemos, / cantand' e con alegria, / quantos seu ben atendemos. Do ponto de vista do significado os dois textos são quase idênticos, a distinção encontra-se principalmente nos significantes, isto é, na língua e na estrutura. Trata-se do mesmo actante, Pierre Siegelar/ Pedro de Sigrar; do mesmo cenário, a igreja de Nossa Senhora de Rocamador; do mesmo instrumento do milagre, a vela que desce três vezes do lustre, instalando-se na viela do jogral; do monge que observa sorrateiramente, tomando o jogral por um mágico; e finalmente, a presença da multidão encantada com o milagre.

A narrativa dojogral de Nossa Senhora foi o ponto de partida para muitas recriações após a Idade Média. O romantismo, que buscou nas fontes medievais a sua matéria, acabou por legarnos duas obras interessantíssimas sobre o jogral e a demonstração de sua fé e devoção. Trata-se de um conto de Anatole France "Le jongleur de Notre Dame", que faz parte de L'Etui de nacre, de 1892. O compositor Jules Massenet também criou, em 1902, com o mesmo título, uma ópera em três atos, com libreto escrito por Maurice Léna. Na realidade, essas duas obras foram produzidas no fim do século XIX, a primeira, e no início do século XX, a segunda, distanciando-se já do romantismo, o que não impede, entretanto, que tenham sido impregnadas dos traços estéticos dessa escola, no que se refere ao interesse pela Idade Média e sua religiosidade.

Como na antiguidade, o mundo medieval vive os milagres como parte importante de sua vida cotidiana, e em consonância com a dimensão real dos fatos, relacionados a numerosos aspectos da experiência humana. Muito se escreveu e se refletiu 
sobre eles, diante da explosão da hagiografia, que a Igreja utilizou no seu papel de intermediária entre o homem e o divino. Surgiram perguntas sobre sua autêntica essência, elaboraram-se explicações "científicas" alternativas, sugeridas pela alquimia, astrologia ou medicina, tentou-se distinguir os prodígios pagãos e os prodígios cristãos, e discutiu-se a questão da autenticidade e credibilidade dos milagres. (cf. CARRERA de la RED, 1996, s.p.).

Como observou com bastante precisão a medievalista Huguette Legros (LEGROS, 1992, p.18) “a estética românica não é uma estética da surpresa, mas sim, uma estética que privilegia a conjuntura e a beleza do estilo. "Fazer um verso novo" é, principalmente, inventar uma forma nova, e não, inventar uma matéria nova". É o estilo, sem dúvida, o traço principal dos poemas, aqui analisados, apresentando, cada um dos poetas, peças que compõem o mais importante repertório mariano da literatura medieval: Les Miracles de Nostre Dame (Coinci) e as Cantigas de Santa Maria.

\section{Apêndice \\ Texto $\mathrm{n}^{\circ} 1$}

Anônimo. Milagre XXXIV: De cereo modulo qui auper vidulam descendit

Petrus Iverni, de Sigelar, instrumenta personando musica victum queritabat. Hic, ex more veniens ad ecclesias, post orationem quam domino fundebat, tangens cordas vidule, laudes Deo reddebat. Qui, cum esset in basilica Beate Marie Rupis Amatoris, diuque psallendo fidibus requiem nullam daret, sed modulatis vocibus interdum instrumento concordans, sursum respexit : "Domina, inquiens, si tibi vel filio tuo Dominatori meo organica placent cantica, quodlibet ex cereis modulis hic sine numero et estimatione pendentibus deponens largire mihi".Cumque in hunc 
modum psallens oraret, et orans psalleret, videntibus qui aderant, modulus unus super instrumentum descendit $(\ldots) .^{3}$

Texto $\mathrm{n}^{\circ} 2$

Gautier de Coinci: La vièle

Vieler vieut un biau son

De la bele

Qui seur toutes a biau non,

En cui Diex devenir hom

Vout jadis

Dont chantent en paradis

Angles et arcangle a haut ton.

La douce mere au creator

A s'eglyse a Rocheamator

Fai tanz myracles tans hauz fais.

Plusieurs fois leü l'ai.

D'un jongleour, d'un home lai

Un mout courtois myracle i truis

Que raconter veil, se je puis,

Pour faire entendre a aucune ame

La cortoisie Nostre Dame.

Ou païs ot un jongleor

Qui de la mere au Sauveor

Chantoit le lai mout volentiers

Quant il venoit par ses mostiers.

Menestreuz ert de grant renon,

Pierre de Sygelar ot non

A Rocheamator ce me samble

Ou granz pueples souvent asamble

En pelerinage en ala.

Mout de pelerins trouva la

${ }^{3}$ In: ALBE, E.; ROCACHER, J., 1975, p. 142. 
[...]

Quant s'orison a dite et faite

Sa vïele a sachie et traite

L'arçon as cordes fait sentir

Et la vïele retentir

Fai si qu'entor sanz nul delai

$S^{\prime}$ asemblent tuit clerc et lai.

Qui de s'ame

Vieut oster le fiel amer

Nostre Dame

Doit jour et nuit reclamer

Fole amor por li amer

Jetons puer

Qui ne l'aime de doux coeur

Bien se puet chetif clamer

Quant saluee ot doucement

Et loee moult longuement

La mere Dieu d'entier corage

Et enclinee ot mout s'ymage

Mout hautement dist et cria

Dame de toute cortoysie

Se il te plait rien que je die

Je te requier qu'en guerredon

$D^{\prime}$ un de ces cierges me fai don [...]

Dame sanz pareille et sanz per,

Pour faire feste a mon souper

Un de tes bialz cierges m'envoie

Plus ne te quier se dieux me voie.

Nostre Dame sainte Marie

Qui fontaine est de cortoysie

Et de douceur source est de dois

Dou menestrel ot bien la vois

Car maintenant sanz plus atendre

Seur sa vïele fait descendre

Tout en apert voiant la gent

Un mout biau cierge et un mout gent. 
Cil et celle

Qui sert par devocion

La pucele

Ou prist incarnation

Por nostre redemption

Li doux Diex

Sen lit a ja fait es ciex

Chambre $\mathrm{i}$ a et manssion

Uns moigne qui ot non Gerars

Qui mout estoir fel et waignars

Qui le mostier adont gardoit

Et qui ces choses regardoit

Com hom plein de melancolie

Le myracle tient a folie.

A Perron dit qu'est enchanteres

Boutencoroye et tregeteres

Entre ses mains le cierge prent

Se le rasiet en haut et pent

Li menestreuz qui assez sot

Le moigne voit enrede et sot [...]

La vïele prend de rechief

Vers l'image lieve le chief

Si chante si bien et vïele

N'est sequence ne kyriele

Qu'escoutissez plus volontiers

Et li cierges biaus et entiers

Seur la viele redescent

Ce myracle virent cinq cent.

[...]

Tuit s'emerveillent tuit se saignent

Au doigt le cierge s'entresaignent

Qui ja deus fois est avalez

Pierre en dormis n'enjalez

$N^{\prime}$ a pas les dois sour la vïele

Mais si bien chante et si viele 
Devant l'ymage Nostre Dame

De pitie fait plorer mainte ame

Quel son que rende la vïele

Li cueur si haut chante et vïele

Que dusqu'a Dieu s'en va li sonz

Car maintenant si com lizons

Au menestrel cui Diex consaut

Ra fait li cierges le tiers saut.

Trois fois la dame li tendi

Quie mielz dou moigne l'entendi

Et qui assez fu plus courtoyse

Dau faut moygne qui de la noise

Est esbaudis et estones

Chascun s'ecrie 'Sonez sonez

Plus biau myracles n'avint mais

Ne n'avenra ce cuit ja mais'.

Virge monde

Por cui Diex monda le mont

Si me monde

Qu'en paradis m'emme mont

$\mathrm{Ti}$ ami ont bien le mont

Seurmonte

Ti ami vont tout monte

Devant Dieu lassus amont

Qui lors veïst le menestrel

Le cierge offrir desor l'autel [...]

Ains fu courtois vaillanz et sages

Car tant com dura ses aages

Chasqu'an si com je truis ou livre

Un mout bel cierge d'un livre

A Rochemador aporta

En Dieu servir se deporta

Et quant Dieu pleut qu'a sa fin vint

A la gloyre du ciel parvint

Et devant Dieu en ala l'âme 
Por la prïere Nostre Dame

Dont il chantoit si volontiers

Et cui d'un cierge estoit rentiers [...]

La clere vois plaisant et bele

Le son de harpe et de vïele

Se psaltere d'orgue de gygue

Ne prise pas Diex une figue

S'il n'a ou cuer devocion

Diex ecoute l'entencion

Non pas la vois ne l'estrument

Qui Dieu loer vuelt doucement [...]

Chantons nos haute kyrieles

Noz sequences nos ymnes beles [...]

Cler sonnera nostre viele

Et no chançons ert bone et bele.

Porte dou ciel

De paradiz, planche et ponz

Sourse de miel

De douceur pecine et fonz.

D'enfer qui tant est parfonz

Nous desfen

Qui nou crient peu a de sen

Car n'i a rive ne fonz.

Douce Dame

Par mout vraie entencion

Cors et ame

Met je en ta protection

Prie sans delation

ten fil douz

Qu'il nos face vivre touz

In terra viventium. Amen. ${ }^{4}$

${ }^{4}$ KOENIG, 1970, v. 4, p. $184-198$. 


\section{Bibliografia citada}

ALBE, E.; ROCACHER, J. Les Miracles de Notre-Dame de Rocamadour au XIIe siècle. Toulouse: Le Pérégrinateur, 1975.

ALFONSO X. Cantigas de Santa Maria. Ed. crit. de Walter Mettmann. Coimbra: Acta Universitatis Conimbrigensis, 1959-72. 4 v. (v. 1)

CARRERA de la RED, Avelina. Creencia y literatura en los Miracula Beatae Mariae Virginis (S. XIII). Cuadernos de Filologia Classica: Estudios Latinos, n. 14, p. 149-165, 1996.

GAUTIER DE COINCI. (Ed. KOENIG, F.) Les miracles de Notre Dame Par Gauthier de Coinci. Genève: Droz, 1955-1970. v. 4, p. 184-198.

KOENIG, Frédéric. Les miracles de Notre Dame. Par Gauthier de Coinci. (ed. F. Koenig). Genève: Droz, 1955-1970. v. 4, p. 184-198.

LE GOFF, Jacques. O maravilhoso e o quotidiano no Ocidente Medieval. Lisboa: Edições Setenta, 1983.

LEGROS, Huguette. La Rose et le Lys. Étude Littéraire du Conte de Floire et Blancheflor. Senefiance. Aix-en-Provence: Publications du CUER MA., n. 31, 1992.

METTMANN, W. (Ed.). Cantigas de Santa Maria. Coimbra: Acta Universitatis Conimbrigensis, 1959-72. 4 v. (v. 1). 


\section{Resumo}

O jogral como figura representativa da religiosidade no período do apogeu do culto mariano será estudado numa perspectiva comparativa, com comentários sóciohistóricos, a partir de uma canção piedosa francesa e de uma Cantiga de Santa Maria.

\section{Résumé}

Le jongleur en tant que figure représentative de la religiosité à l'apogée du culte marial, sera étudié dans une perspective comparative, suivie de commentaires socio-historiques, à partir d'une chanson pieuse française et d'une cantiga de Santa Maria. 